\title{
Editorial
}

\section{Asset optimization and multi-resource planning}

What kinds of resources should a company deploy or engage? In what quantities? In what relative proportions? What about their quality, capacity and reserves? How should a portfolio of resources be changed from period to period? What kind of assets should be dedicated, flexible and optimized?

In other words: How does one optimize corporate assets and their deployment and use? Does optimization of asset and resource portfolio matter?

It does and in fact the portfolio of resources distinguishes lean and flexible corporations from slow and bloated ones. Haphazardly and capriciously assembled resources, human, physical, technological and financial, force huge and persistent tradeoffs into corporate decision making and strategy setting. Tradeoffs have always been evil and in modern management are not even necessary.

Asset optimization directly reduces or even eliminates corporate tradeoffs. Tradeoffs elimination, i.e., tradeoffs-free management, is rapidly becoming the corner stone of a successful globally competitive strategy.

Consider a simple production problem involving two different products, say suits and dresses, in quantities $x$ and $y$, each of them consuming five different resources (nylon through golden thread) according to technologically determined requirements (technological coefficients). Unit market prices of resources are also known, as are the levels (no. of units) of resources currently available (portfolio of resources). The data are summarized in Table 1.

In the above example, observe that producing one unit of each product $x$ and $y(x=1$ and $y=1)$ requires four units of nylon $(4 \times 1+0 \times 1)$, eight units of velvet $(2 \times 1+6 \times 1)$, etc. The total number of available units of each material (given resource portfolio) is given in the last column of Table 1 .

Current market prices of resources (first column) allow us to calculate the costs of the initial resource portfolio:

$$
\begin{aligned}
& (30 \times 20)+(40 \times 24)+(9.5 \times 60) \\
& \quad+(20 \times 10.5)+(10 \times 26)=\$ 2600 .
\end{aligned}
$$

The same prices can be used to compute unit of producing one unit of each of the two products:

$$
\begin{array}{r}
x=1: \quad(30 \times 4)+(40 \times 2)+(9.5 \times 12) \\
+(20 \times 0)+(10 \times 4)=\$ 354, \\
y=1: \quad(30 \times 0)+(40 \times 6)+(9.5 \times 4) \\
\quad+(20 \times 3)+(10 \times 4)=\$ 378 .
\end{array}
$$

In other words, it costs $\$ 354$ to produce one suit and $\$ 378$ to produce one dress. Suppose that we can sell all we produce at current market prices of $\$ 754 /$ unit of $x$ and $\$ 678 /$ unit of $y$.

Expected profit margins (price-cost) are:

$$
\begin{aligned}
& x: 754-354=\$ 400 / \text { unit } \\
& y: 678-378=\$ 300 / \text { unit. }
\end{aligned}
$$

As profit maximizers, we are interested in maximizing the total value of function $f_{1}=400 x+300 y$.

As a second criterion let us consider some quality index: say 6 points per $x$ and 8 points per $y$ (scale from 0 to 10 ), so that we can maximize the total quality index or function $f_{2}=6 x+8 y$.

We are now in a position to analyze the above outlined production system with respect to profits and quality. Maximizing levels of $x$ and $y$ (best product mix) can be easily calculated by techniques of linear programming (here we use only the results).

1) Function $f_{1}$ is maximized at $x=4.25$ and $y=2.25$, thus achieving a maximum of $(400 \times$ $4.25)+(300 \times 2.25)=\$ 2375$ in profits.

2) Function $f_{2}$ is maximized at $x=3.75$ and $y=$ 2.75 , achieving a maximum of $(6 \times 3.75)+(8 \times$ $2.75)=44.5$ in total quality index.

Clearly, one can trade off quality for profits by moving from $x=3.75, y=2.75$ to $x=4.25, y=2.25$ 
Table 1

Initial data for production example

\begin{tabular}{|c|c|c|c|c|}
\hline \multirow[t]{2}{*}{$\begin{array}{l}\text { Unit price } \\
(\$)\end{array}$} & \multirow[t]{2}{*}{$\begin{array}{l}\text { Resource } \\
\text { (Raw material) }\end{array}$} & \multicolumn{2}{|c|}{$\begin{array}{l}\text { Technological coefficients } \\
\text { (Resource requirements) }\end{array}$} & \multirow[t]{2}{*}{$\begin{array}{l}\text { No. of units } \\
\text { (Resource portfolio) }\end{array}$} \\
\hline & & $x=1$ & $y=1$ & \\
\hline 30 & nylon & 4 & 0 & 20 \\
\hline 40 & velvet & 2 & 6 & 24 \\
\hline 9.5 & silver thread & 12 & 4 & 60 \\
\hline 20 & silk & 0 & 3 & 10.5 \\
\hline 10 & golden thread & 4 & 4 & 26 \\
\hline
\end{tabular}

Table 2

New data for production example

\begin{tabular}{|c|c|c|c|c|}
\hline \multirow[t]{2}{*}{$\begin{array}{l}\text { Unit price } \\
\qquad(\$)\end{array}$} & \multirow[t]{2}{*}{$\begin{array}{l}\text { Resource } \\
\text { (Raw material) }\end{array}$} & \multicolumn{2}{|c|}{$\begin{array}{l}\text { Technological coefficients } \\
\text { (Resource requirements) }\end{array}$} & \multirow[t]{2}{*}{$\begin{array}{l}\text { No. of units } \\
\text { (Resource portfolio) }\end{array}$} \\
\hline & & $x=1$ & $y=1$ & \\
\hline 30 & nylon & 4 & 0 & 16.12 \\
\hline 40 & velvet & 2 & 6 & 23.3 \\
\hline 9.5 & silver thread & 12 & 4 & 58.52 \\
\hline 20 & silk & 0 & 3 & 7.62 \\
\hline 10 & golden thread & 4 & 4 & 26.28 \\
\hline
\end{tabular}

and back again, exchanging profits for quality. Because we can produce only one product mix at a time, we can choose to either maximize profits $(x=$ $4.25, y=2.25)$ or maximize quality $(x=3.75, y=$ $2.75)$, but not both. The choice is difficult because of the tradeoffs between profits and quality.

Let us now optimize and purchase a portfolio of resources that is different from that in Table 1, other things being equal. We keep this new production system comparable and compatible in all respects, except the last column of Table 1. The new portfolio of resources is in Table 2.

We are now in a position to analyze the newly proposed production system under the same conditions.

1) Function $f_{1}$ is now maximized at $x=4.03$ and $y=2.54$, achieving a maximum of $(400 \times$ $4.03)+(300 \times 2.54)=\$ 2375$ in profits.

2) Function $f_{2}$ is maximized at $x=4.03$ and $y=$ 2.54 , achieving a maximum of $(6 \times 4.03)+(8 \times$ $2.54)=44.5$ in total quality index.

Both previously achieved maximum values of $f_{1}$ and $f_{2}$ have been matched. More importantly, both maximum profits (\$2375) and maximum quality in- dex (44.5) are achieved through a single product mix: $x=4.03$ and $y=2.54$. This particular product mix was infeasible in the previous system and was reached through resources optimization. By allowing its feasibility we have eliminated all and any tradeoffs between the criteria of profits and quality.

The previous tradeoffs-based system (Table 1) was operated at the cost of $\$ 2600$. The newly designed tradeoffs-free system (Table 2) is realizable at the following cost:

$$
\begin{aligned}
& (30 \times 16.12)+(40 \times 23.3)+(9.5 \times 58.52) \\
& +(20 \times 7.62)+(10 \times 26.28)=\$ 2386.74 .
\end{aligned}
$$

The superior performance of the newly designed system comes actually at $\$ 213.26$ cheaper than the already suboptimal performance of the original system. Better systems are usually cheaper, ideal systems come at no additional costs.

The above example demonstrates that the selected portfolio of resources is crucial for assessing maximum achievable levels of profits, costs, quality, flexibility, etc., at which corresponding production systems can be operated. 
In our example, should any company choose to operate any other resource portfolio (at cost $\leqslant \$ 2600$ ) than that of Table 2 (i.e., optimal), other things being equal, then its performance with respect to $f_{1}$ and $f_{2}$ would be necessarily inferior.

The explanation is simple. Productive assets and resources should not be engaged individually and separately because they do not contribute one by one according to their marginal productivities. Productive resources perform best as a whole system: they should be determined and engaged jointly as a portfolio and in an optimal fashion.

Consequently, any company running any other than optimal portfolio of resources cannot outperform a company running the optimal portfolio, ceteris paribus.
We have identified the portfolio of resources to be the key to a system's potential performance and maximum productivity. The issues of technology, education, skills, work intensity, innovation, flexibility, quality, etc., are all very important in business. But they could only come to their full fruition if applied to an optimally designed, tradeoffs-free system.

Milan Zeleny Graduate School of Business Fordham University at Lincoln Center New York, NY 10023 